\title{
Movimiento de redención ecológica de la cuenca del Río Piracicaba: una experiencia de acción colectiva*
}

The ecological redemption movement of the Piracicaba river basin: a collective action experience

Miguel Hernández [l]

\section{Resumen}

El antecedente del modelo de gestión de agua brasileño tiene su origen en los complejos procesos de degradación ambiental y los conflictos en torno a las exigencias hídricas desde la década de los años setenta. En ese sentido, la experiencia del estado de São Paulo es central, puesto que fue en las cuencas de los ríos Piracicaba, Capivari y Jundiaí (PCJ), donde la participación de ciudadanos a través del Movimento de Redención Ecológica Año 2000 empujó a la conformación de un modelo de gestión regional de agua basado en la descentralización y la participación de diversos actores sociales. Los impactos de ese movimiento sociambiental dieron origen a instancias que hasta la fecha han servido de base en la gestión de recursos hídricos en Brasil.

Palabras clave: movimiento socioambiental; Piracicaba; Consorcio PCJ; agua y saneamiento; Brasil.

\begin{abstract}
The antecedent of Brazil's water management model has its origins in the complex processes of environmental degradation and in conflicts concerning water requirements that have been occurring since the 1970s. In this sense, the experience of the state of São Paulo is central, since it was in the basins of the Piracicaba, Capivari and Jundiaí (PCJ) rivers that the participation of citizens, by means of the Year 2000 Ecological Redemption Movement, impelled the configuration of a regional water management model based on decentralization and on the participation of various social actors. The impacts of this socioenvironmental movement gave rise to spheres that have been serving, to this day, as the basis for the management of water resources in Brazil.
\end{abstract}

Keywords: socio-environmental movement; Piracicaba; PCJ Consortium; water and sanitation; Brazil. 


\begin{abstract}
Mi relación con el río es muy fuerte. La pesca está desde hace cuatro generaciones en mi familia. Soy nacido y criado en la calle del Puerto, entonces puedo decir que el Piracicaba estuvo presente en toda mi vida, antes de que yo naciera, pues mi abuelo y mi padre eran pescadores. Cuando mi hijo Zize tenía seis años, acostumbraba a llevarlo conmigo para pescar. Como él era muy pequeño y tenía miedo de caer del barco, amarraba su pierna y le enseñaba el oficio. Hoy, él es uno de los pescadores más conocidos de la ciudad. No sé qué sería de mi vida si no tuviéramos el río. A través de él conseguí crear a mis hijos y hoy él todavía es la base del sustento de toda mi familia.
\end{abstract}

(Aguas do Mirante, 2014)

\section{Introducción: del movimiento social a la conformación de modelos de gestión de agua}

Históricamente los movimientos y las protestas sociales impulsadas por ciudadanos organizados han sido determinantes en la construcción de espacios de participación incluyentes y deliberativos. Ahí se discuten, analizan y proponen alternativas para solucionar problemas que afectan a todos los ciudadanos. Así, a partir de la existencia de un problema que afecta a los miembros de una comunidad, independientemente de sus creencias, trayectorias o filiaciones políticas, la sociedad civil organizada recurre a diferentes formas de acción colectiva, llámense protestas, manifestaciones o movimientos sociales con impacto, como el que ocurrió en la ciudad de Piracicaba entre finales de la década de los años setenta y a lo largo de los años ochenta. Este movimiento socio ambientalista, originado por la contaminación del río que le dio nombre dicha urbe, fue importante en la consolidación de un modelo de gestión de recursos hídricos, cuyos impactos se manifestaron en diferentes escalas: local, regional o intermunicipal, estatal y federal.
Existe una amplia bibliografía sobre el origen, desarrollo e impacto de los movimientos sociales. Para entender al movimiento de la ciudad de Piracicaba en este texto se han retomado las ideas de McAdam (1999, pp. 19-21), quien considera que existen tres factores básicos en el análisis de revoluciones, movimientos o protestas sociales: 1) las oportunidades políticas, que se expresan en situaciones y contextos sociohistóricos que hacen posible el surgimiento de descontentos y formas de acción colectiva; 2) las estructuras de movilización, que manifiestan formas de organización tanto formales o informales impulsadas por los diferentes actores sociales; y 3) los procesos enmarcadores, es decir, la combinación de las dos primeras que encarnan procesos colectivos de interpretación, atribución y construcción social que median la oportunidad y la acción. Por otro lado, siguiendo las ideas de Moore (1996), existe un sentimiento de agravio moral, elemento fundamental en el surgimiento de una conciencia colectiva que anima a la organización de diversos sectores de la sociedad. Dicho sentimiento, además de estar enmarcado en aspectos justicia y reconocimiento de derechos sociales, también 
trastoca a otras expresiones de la conducta social como las emociones, la identidad y la cultura. Aquí, los símbolos se consolidan en un elemento de cohesión social, como lo fue el río en el caso que aquí se analiza.

Por otro lado, para entender este movimiento ambientalista es necesario considerar ese hecho en el marco del proceso democratización de América Latina, de manera especial en Brasil durante el último periodo de la dictadura militar y el inicio del proceso de democratización que dio origen al fortalecimiento de diversos movimientos sociales y expresiones de acción colectiva. En la ciudad de Piracicaba existieron dos momentos clave en la consolidación de expresiones de acción colectiva. Entre 1964 y final de la década de 1970 proliferaron diferentes expresiones organizativas, cada una con sus agendas pero que en esencia expresaban su crítica a la dictadura militar. Por otro lado, después de la primera mitad de la década de 1980 y hasta finales de la década de 1990 se generaron condiciones políticas que fortalecieron las expresiones de organización de ciudadanos (Teixeira, 2006), principalmente a partir de la degradación del río Piracicaba y los recurrentes problemas de abastecimento de agua en el municipio del mismo nombre (ver Cuadro 1).

La construcción democrática es un proceso, una lucha por la hegemonía en la que participan diferentes actores sociales articulados de diferente manera y que defienden diferentes proyectos políticos, entendidos como una "combinación de intereses, ideas, valores, principios y programas de acción" (Dagnino, 2006, p. 9). En su sentido más amplio, la construcción democrática no termina sólo y únicamente con la democracia electoral, sino que se refiere "la ampliación de nuevas esferas de la vida pública" y a la extensión de su concepto de política ciudadana. Estos procesos se caracterizan por su complejidad y están determinados por las condiciones históricas nacionales, regionales y locales, así como por las condiciones globales en las que han jugado un papel determinante la intervención de agencias multilaterales, redes internacionales de ONG's y movimientos sociales alternativos; todo ello, en un contexto donde están confrontados dos proyectos políticos: el neoliberal y el democrático participativo que, como indica Dagnino (2006, p. 9), "tienen como telón de fondo la herencia cultural e institucional, mayor o menor según cada nación". En este enfoque se busca conceptualizar la práctica de actores sociales y políticos para entender las condiciones y circunstancias en las que impulsan sus proyectos. Esto incluye la caracterización de las coyunturas y contextos que consolidan diferentes proyectos participativos (Dagnino, 2006; Teixeira, 2003; Isunza, 2006a; Isunza, 2006b; Isunza, 2014; Feltran, 2006).

El movimiento ambiental generado en la ciudad de Piracicaba se conforma en un escenario donde el Estado, concebido como una entidad heterogénea (Dagnino, 2006, p. 16), juega un papel fundamental en la conformación de situaciones que animan a ciertos actores sociales a la utilización de recursos para generar diversas formas de acción social (Tarrow, 1999, pp. 97-99). Esta idea remite a la relación entre sociedad civil y el Estado dentro espacios de intercambio y conflicto, conformando interfaces socioestatales 
"determinadas estructuralmente tanto por la política pública en la que se insertan como por los proyectos sociopolíticos de los actores (estatales y societales) concernidos" (Isunza, 2006a, p. 271).

El movimiento socioambientalista analizado en este artículo se constituye, por un lado, como una de las expresiones de la ciudadanía que colocó en la agenda pública el severo problema de degradación del río Piracicaba; por el otro, es una antecedente para la generación de nuevos esquemas de gestión de recursos hídricos, ya que todas las acciones se orientaron bajo el principio de que eran necesarias soluciones integrales que atendieran tanto los aspectos vinculados al bienestar común de la población en sus diferentes escalas: local, regional y estatal. Como movimiento social, destaca el hecho de que se en plena década de los años ochenta se adoptara el nombre de "Campaña año 2000, Redención de la Cuenca del Piracicaba", puesto que como plantea Tilly (2010, p. 22), a diferencia de una petición única o declaración, una campaña no se detiene en un sólo episodio. Se trata de un proceso continuo con mayor proyección.

Con base en esos antecedentes, en este texto se describirá el proceso de movilización de la ciudadanía en un contexto de transición de un régimen militar a uno democrático en Brasil y, finalmente, analizar cómo la agenda que se constituyó durante ese periodo repercutió en la creación de un modelo institucional para el estado de São Paulo y posteriormente para la Unión Federativa brasileña.
Ciudad e impactos de un modelo de desarrollo industrial sobre el Río Piracicaba

Piracicaba es una palabra de origen guaraní: pira [pez], cycaba [sin fin]; es decir, "abundancia de peces" o "peces sin fin" (Costa, 2004, p. 38). Esta característica fue determinante para el establecimiento de una relación entre el río y los habitantes de la ciudad. Además de la pesca, el cultivo de caña destinada a la industria agroquímica se constituyó como una de las actividades económicas más importantes después de la segunda mitad del siglo XX (Gallo, 2000). El río Piracicaba le da nombre a tres unidades administrativas: a una de las cuencas más importantes del estado de São Paulo; al municipio y a la ciudad.

Piracicaba, ciudad ubicada en el sudeste del estado de São Paulo, se conformó como un núcleo urbano donde históricamente la industria ha sido una actividad económica fundamental (ver Mapa 1). Fue fundada el $1^{\circ}$ de agosto de 1767 y antes de convertirse en la ciudad que hoy en día es, éste era un poblado que estuvo supeditado a una antigua colonia y base militar llamada Nuestra Señora de los Placeres de Iguatemí donde servía como un espacio estratégico en la exploración de nuevas tierras para posteriormente colonizarlas (Teixeira, 2009, pp. 27-29). Así, su ubicación en la margen derecha el río del mismo nombre hizo posible que se convirtiera en un poblado donde la fabricación de barcos 


\section{Mapa 1 - Ubicación geográfica del Municipio de Piracicaba}

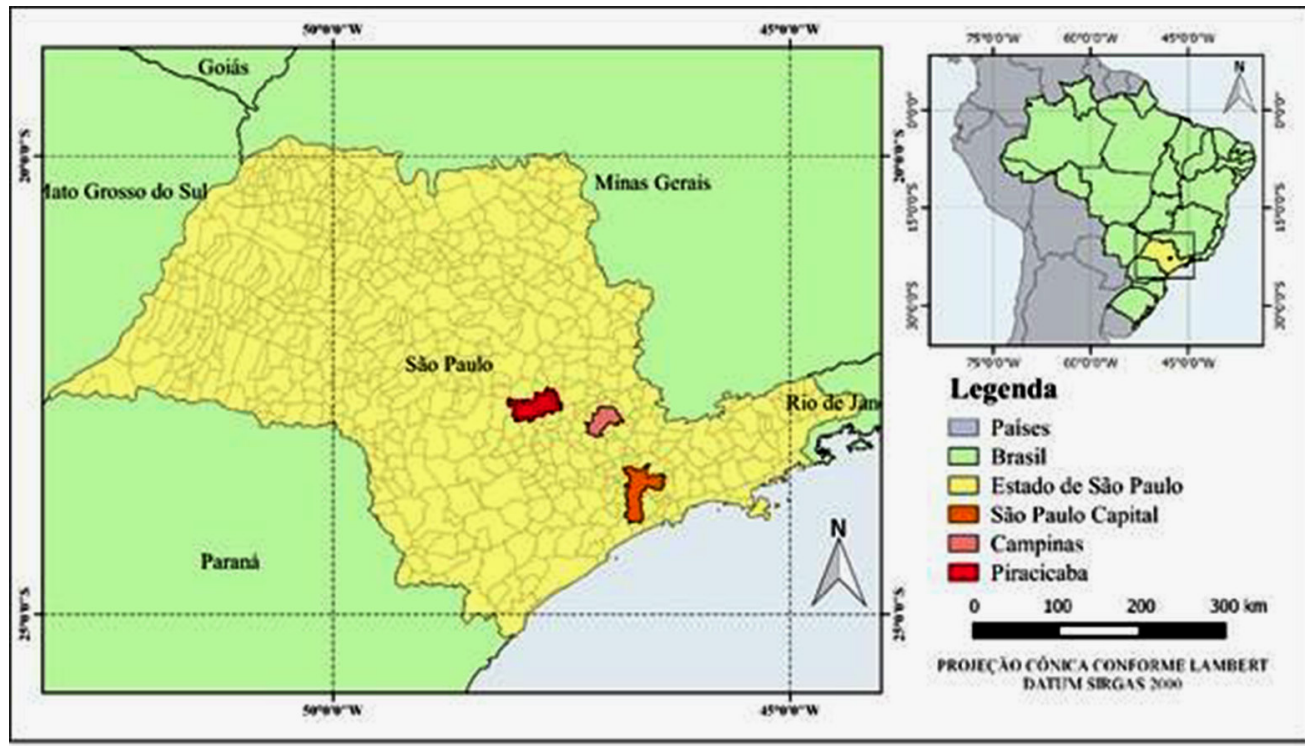

Fuente: IBGE (2016).

se consolidó como una de las principales actividades productivas. Ese fue quizá el primer antecedente de industrialización en esa región

A finales del siglo XIX, el poblado se había constituido como un núcleo urbano con una vida social intensa. Era uno de los escenarios culturales y políticos más importantes al interior del estado de São Paulo y para ese tiempo, incluso, se le llegó a conocer como la "Atenas Paulista" (Costa, 2004). Siguiendo los planteamientos de Teixeira (2009, p. 90), la relación entre urbanización, industrialización y cultura es fundamental para entender el desarrollo de Piracicaba como ciudad. A partir de la segunda mitad del siglo XX experimentó un rápido crecimiento de la población. De acuerdo con los datos del Instituto de Investigaciones y Planeación de Piracicaba
(Instituto de Pesquisas e Planejamento de Piracicaba) entre 1980 y 2014 la densidad poblacional de habitantes en el municipio se incrementó casi al doble (ver Cuadro 1).

Por sus características geográficas, el patrón de crecimiento urbano se ha dado a lo largo de casi 20 kilómetros sobre las márgenes del río Piracicaba en una topografía poco accidentada y que hoy en día ocupa un área territorial municipal de 1,378,50 $\mathrm{Km}^{2}$, dentro de la que 229,66 $\mathrm{Km}^{2}$ corresponden al área de ocupación urbana y 1,148,84 Km² al área rural (Instituto de Investigaciones y Planeación de Piracicaba, 2010) (ver Mapa 2). Como sucedió en gran parte de esa región, a partir de la década de los años sesenta se intensificaron los procesos de crecimiento poblacional y expansión urbana. Estos 
Cuadro 1 - Densidad demográfica del crecimiento de la población en la ciudad de Piracicaba

\begin{tabular}{|c|c|}
\hline Año & Densidad demográfica (hab./km²) \\
\hline 1980 & 145,04 \\
1985 & 165,34 \\
1990 & 187,43 \\
1995 & 218,84 \\
2000 & 239,97 \\
2014 & 272,29 \\
\hline
\end{tabular}

Fuente: Instituto de Pesquisas e Planejamento de Piracicaba (http://ipplap.com.br/site/piracicaba-em-dados); Fundação Seade.

Mapa 2 - Área urbana de la ciudad de Piracicaba e hidrografia del municipio

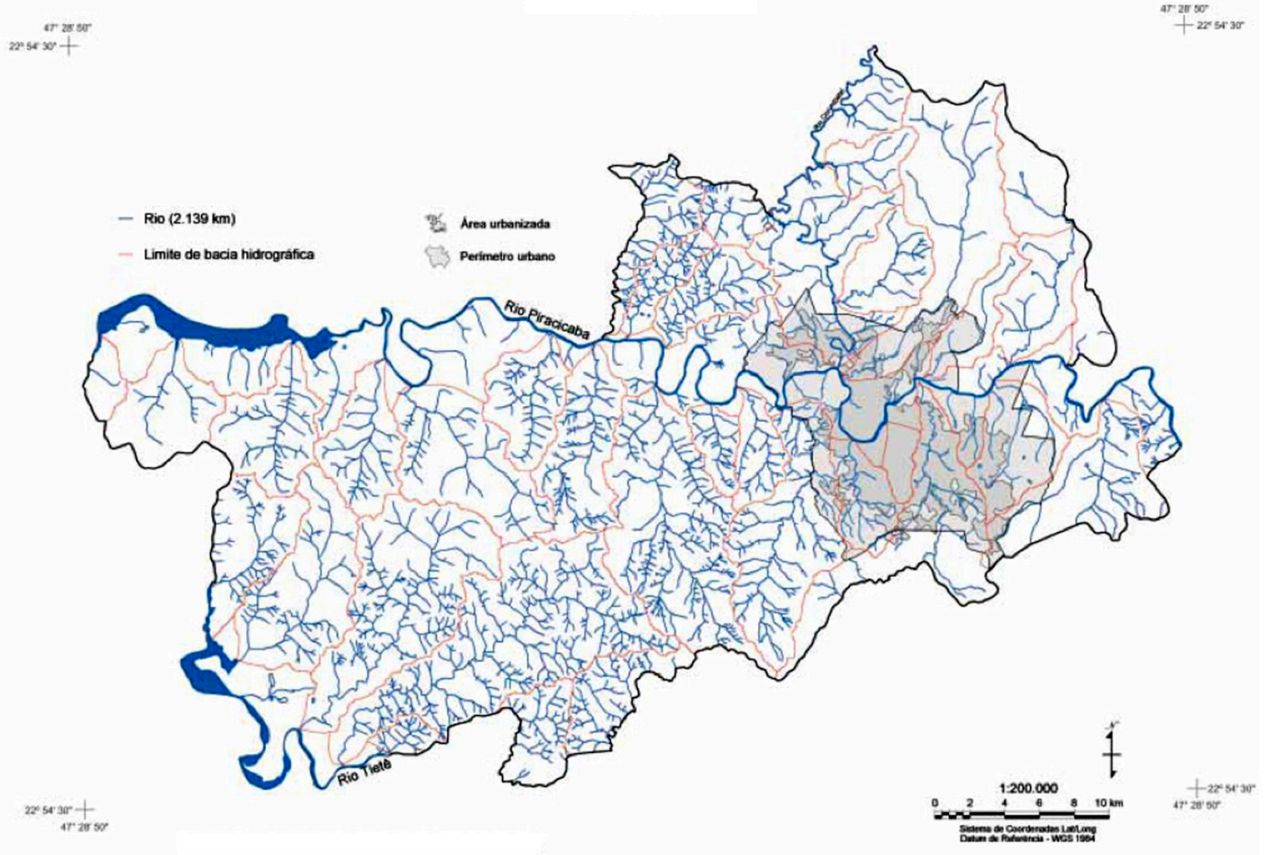

Fuente: IPEF (2006). 
fenómenos están estrechamente vinculados con el auge de la industria en las regiones de Campinas y Piracicaba. De esta forma, tanto la región administrativa de Campinas y Piracicaba aumentaron de manera significativa su participación en el Ilamado "Valor de la Transformación Industrial" en el estado de São Paulo, llegando a su máximo nivel para la década de los años setenta.

Todo ese crecimiento y bonanza económica estuvo acompañado de un proceso modernizador que diversificó el parque industrial en los rubros de química, petroquímica y mecánica. Además del desarrollo en este ámbito, ambas regiones también experimentaron el fortalecimiento de sus actividades agropecuarias, consolidando unidades agro-industriales donde destaca la producción de azúcar y alcohol, así como la producción pecuaria y avícola. Los impactos de estos procesos se hicieron evidentes en el ámbito urbano y ambiental, siendo Piracicaba, por su ubicación geográfica, uno de los municipios más afectados por la contaminación de su río. La bonanza económica que se experimentó en la región de Campinas tuvo su otra cara de la moneda en esta ciudad. Las consecuencias negativas se expresaron en la degradación del río Piracicaba. La presión que ejerció la industrialización sobre el afluente, así como el crecimiento de la ciudad puso en crisis el sistema de abastecimiento de agua para consumo doméstico. Las aguas del río ya no eran aptas para el consumo humano; los peses morían y las actividades cotidianas (pesca y navegación) de los habitantes de la ciudad también se vieron limitadas.
Si bien las descargas de aguas contaminadas que provienen de los ríos Atibaia y Jaguari, ubicados en la región de Campinas, representan una fuente de contaminación, vale la pena destacar que también en el municipio de Piracicaba las actividades vinculadas a la producción de caña y azúcar son otra fuente de contaminación (ver Mapa $3)$. De acuerdo con Gallo (2000, p. 44), "las plantas de azúcar y alcohol [...] generaban una potencial fuente de contaminación, que equivalía a la generada por una población de cerca de 16 millones de personas".

En esencia, el modelo de desarrollo sustentado en la actividad industrial fue el sello que distinguió a la economía del estado de São Paulo durante la segunda mitad del siglo $X X$. Este desarrollo implicó la explotación de diversos recursos naturales, siento el agua un elemento central para la producción de energía eléctrica, la creación de áreas de cultivo y el suministro de servicios de agua potable en diversas ciudades (Carmo, 2001a; Carmo, 2001b). Las consecuencias de este hecho se hicieron visibles en diferentes micro-espacios en Piracicaba y otras ciudades. Ejemplo de ello es el siguiente relato de un ciudadano:

Cuando nos mudamos para el barrio, hace 18 años, el olor era ya muy fuerte. Teníamos vergüenza de recibir visitas, porque daba la impresión de que el mal olor venía de la casa. Por eso, acabamos gastando mucho con productos de limpieza. El verano era la época en que el problema era más evidente. Por culpa del mal olor, la casa tenía que estar toda cerrada. Con el tiempo, pensamos en la posibilidad de vender la casa. Estábamos 
con dolores de cabeza constantes y también problemas respiratorios. Además de eso, hubo un aumento significativo de insectos. (Testimonio de Solange, en: Aguas do Mirante, 2014, p. 45) [La traducción es nuestra]

Además de la contaminación y sus efectos en la calidad de vida de los ciudadanos, principalmente en el ámbito de la salud, las situaciones de escasez de agua fueron más recurrentes a partir de la construcción del Sistema Sistema Cantareira en 1960 para satisfacer la demanda de agua de la Grande São Paulo. El sistema Cantareira fue la solución que el gobierno del estado de São Paulo dio ante el crecimiento de la población y la demanda de agua en la capital. El sistema se conforma por 5 represas y acueductos que captan el agua de los ríos Piracicaba, Atiabía y Jaguatibaia para canalizarla hacia la capital del estado.

El Sistema Cantareira ocupa un área de 228 hectáreas y es considerado uno de los mayores sistemas de producción de agua en el mundo. Fue construido entre la década de los años sesenta y setenta con el fin de satisfacer la demanda de agua potable de São Paulo y su región metropolitana. Hoy en día más de 19 millones de ciudadanos asentados en 12 municipios (8 en el estado de São Paulo y 4 en el de Minas Gerais) dependen de él. De acuerdo con las estimaciones técnicas, produce alrededor de 33 mil litros de agua por segundo y la totalidad de las aguas provienen del río Piracicaba que finalmente terminan en la cuenca del alto Tietê, en la región conocida como la "Grande São Paulo" (Whately y Cunha, 2007, p. 13).

Mapa 3 - Delimitación hidrográfica de las Cuencas de los río Piracicaba, Capivari y Jundiaí. Municipios que integran al Consorcio Intermunicipal PCJ

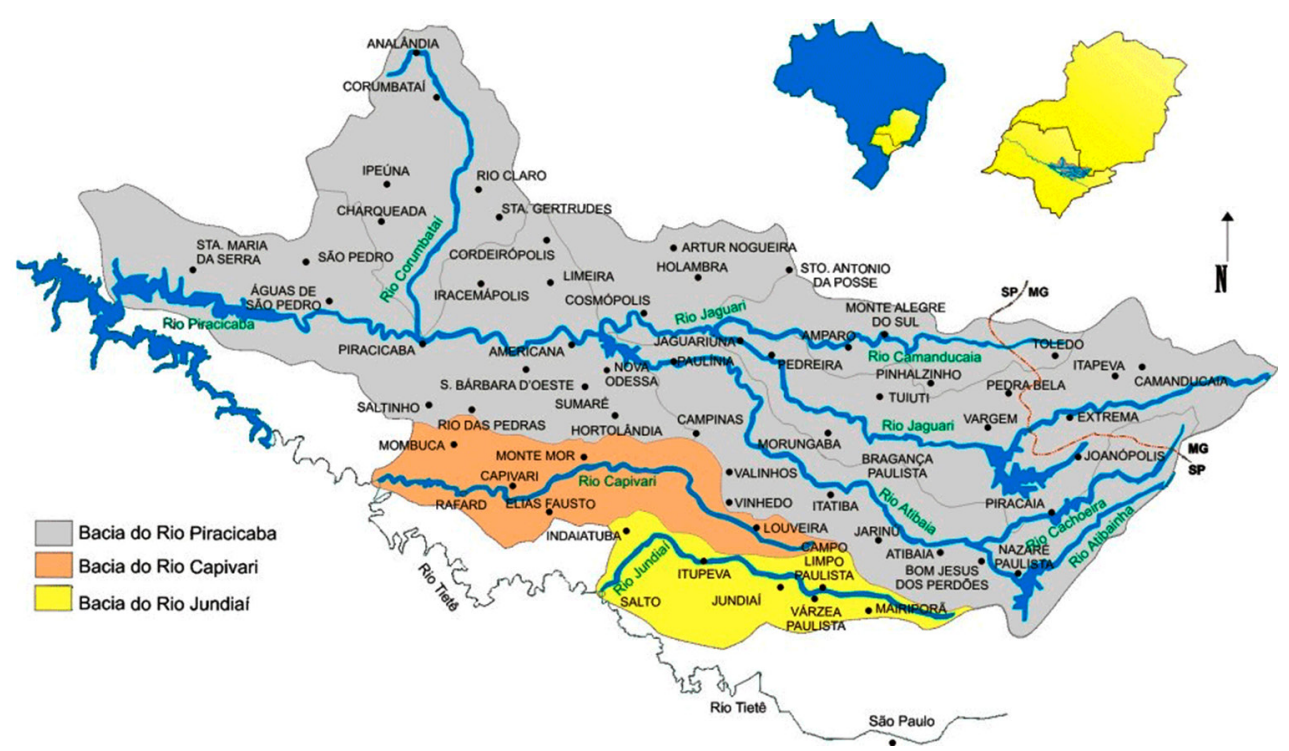

Fuente: https://agua.org.br/nossa-area-de-atuacao/ 
El Sistema forma parte de uno de los macroproyectos más importantes en el estado; aunque su planeación se remonta desde una década anterior, motivada por el crecimiento de la población y por los recurrentes problemas de escasez que afectaron a varios municipios del estado. Además, el consumo de recursos hídricos experimentó un notable aumento a partir del cultivo de caña utilizada para la producción de alcohol, actividad que el gobierno del estado promovió a partir de 1975 mediante la implementación de programas como el Programa Nacional de Alcohol, en el marco de la crisis de combustibles derivados del petróleo en 1973. De esta manera, el abastecimiento de agua tanto para las los ámbitos rurales y urbanos creció a niveles nunca antes experimentados. El proceso de explosión demográfica, fortalecimiento de la industria y la agricultura irrigada llevaron a la erradicación del $90 \%$ de la vegetación endémica. Estos problemas se tradujeron en recurrentes problemas de escasez de agua, registrándose índices de baja disponibilidad de agua, similares a los contextos de los países como Argelia o Ruanda (Liana, 2010, p. 42).

La experiencia de Piracicaba y otras ciudades del interior de São Paulo muestra la estrecha relación entre ciudad y modelo de desarrollo. Se trata de un modelo de ciudad urbanocéntrico, donde la ciudad que funge como principal polo de desarrollo (en este caso São Paulo) satisface sus necesidades o impone un modelo de desarrollo en el que la expansión urbana y modelos productivos (industria y agroindustria) están vinculados. En este modelo, São Paulo se constituye como la ciudad que funge como principal polo de desarrollo y articula los recursos hídricos en la región, dando prioridad a sus necesidades y demandas, sin considerar la posibilidad de dejar sin agua a algunos municipios 0 contaminar las aguas de otros. En ese modelo de desarrollo urbanocéntrico no sólo se da prioridad a las actividades productivas o a la demanda de agua para las principales ciudades, sino que dispone de los recursos naturales en una escala regional sin ningún principio de sustentabilidad (Perló, 2005; Peña, 2013). Así, las soluciones técnicas se constituyen como la principal alternativa de mejora y se encarnan en proyectos tan grandes como el Sistema Cantareira, que va disponiendo del agua de diversos afluentes para garantizar el abastecimiento de agua en la Grande São Paulo. Lejos de generar soluciones a largo plazo, estos planes fortalecen las brechas de desigualdad, exponiendo las personas a situaciones de escasez de agua o problemas de salud por la presencia de aguas contaminadas.

\section{Acción colectiva frente a la degradación del río Piracicaba}

Una de las primeras impresiones para quien visita la ciudad de Piracicaba es su río. En algunos puntos de la ciudad alcanza más de 300 metros de ancho y el notable sonido que se produce por la fuerza de la corriente de agua en algunas zonas empedradas hace evidente su fuerza. El paisaje de las márgenes del río está formado por diversos elementos modernos y antiguos, que al pasar del tiempo coexisten y le dan a ese espacio un sello único; en las márgenes convergen 


\section{Río Piracicaba, estado de São Paulo}

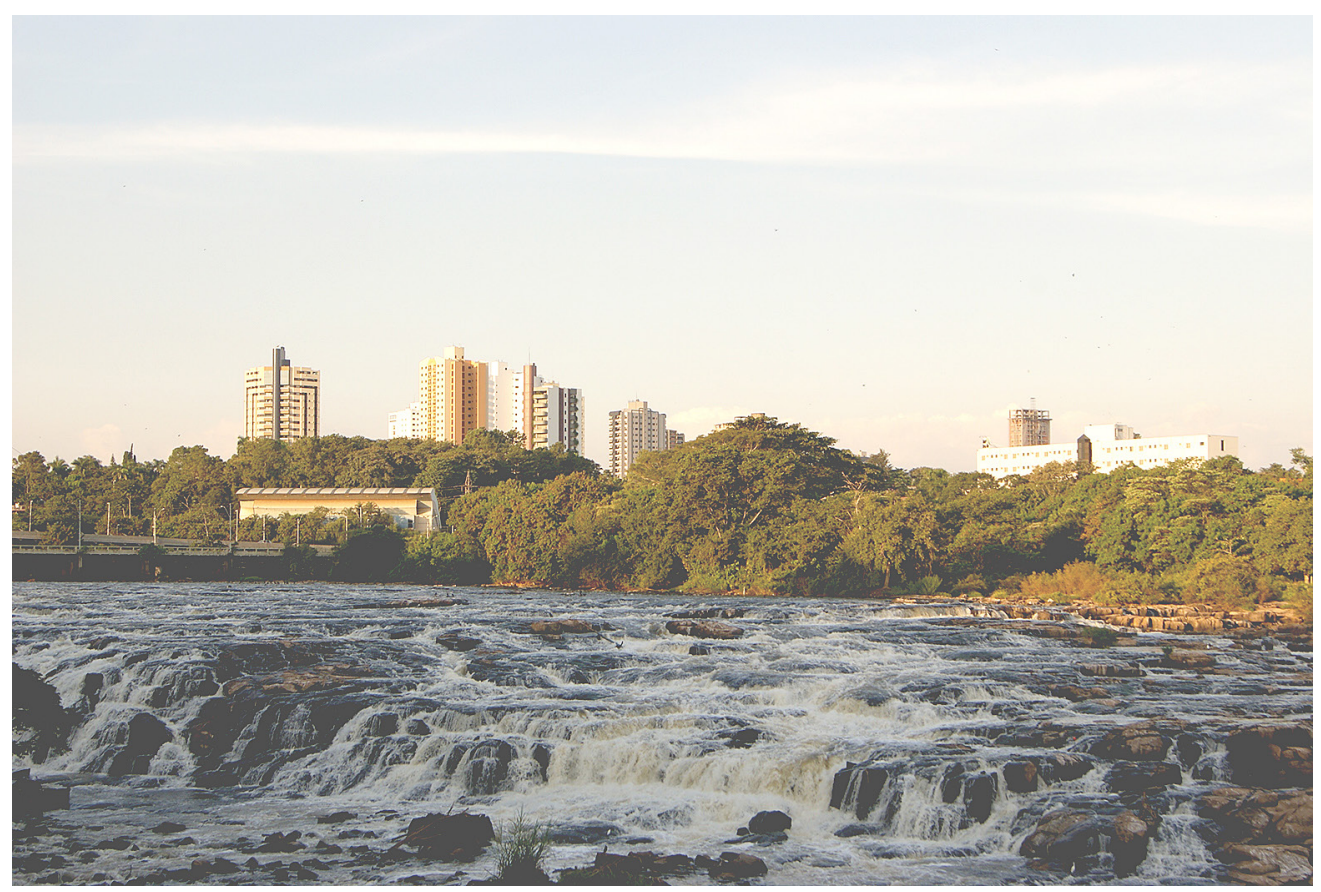

Foto: Miguel Hernández Hernández. 2013.

avenidas modernas, casas que siguen el patrón arquitectónico del siglo XIX, edificios modernos y el antiguo ingenio de azúcar, uno de sus principales símbolos que entre finales del siglo XIX e inicios del siglo XX se consolidó como uno de los principales motores de la economía regional (Hernández, 2015).

Fue en este escenario en el que desde tiempos de la dictadura militar se comenzó a generar una conciencia participativa. El golpe militar de 1964 se manifestó de manera especialmente violenta en esta ciudad. Todos los intentos de organización ciudadana fueron reprimidos, quedando líderes encarcelados y generándose un clima de confrontación, ya que también había núcleos de ciudadanos que apoyaban a la dictadura. En las narraciones de ciudadanos de Piracicaba que vivieron ese tiempo Beatriz Vicentini (Polacow, 2014, p. 110) destacó lo siguiente:

El clima de intimidaciones continuó de diversas maneras a lo largo de los años y en las siguientes décadas, acosando ciudadanos comunes pero, principalmente, al medio académico de las universidades y liderazgos que, de alguna manera, procurarían desafiar al régimen militar. (La traducción es nuestra) 
Sin duda alguna, la dictadura militar representó para la sociedad brasileña un retroceso en los procesos de participación ciudadana, la cual comenzaba a generar importantes avances en la construcción de espacios democráticos. Como señala Assis de Almeida (2006, p. 390), durante más de dos décadas, entre los años de 1964 y 1985, Brasil estuvo gobernado por una dictadura heterogénea pero que se caracterizaba por su autoritarismo, ilegitimidad y arbitrariedad. A diferencia de las dictaduras de Argentina y Chile, la brasileña constituyó un modelo represivo menos visible por el aparente consentimiento de algunos ciudadanos.

Al inicio de la dictadura militar en 1964 , pocas voces osaron en condenar las detenciones arbitrarias y la tortura impuesta sobre militantes políticos, defensores del régimen constitucional anterior y miembros de sindicatos y organizaciones estudiantiles. Entretanto, en la medida en que la intensificación de la represión política comenzó a afectar a los miembros de la élite, clamores y protestas estallaron invocando temas de derechos humanos en los casos de abuso por parte de militares. En la década de 1970, el énfasis recayó sobre las violaciones a los derechos civiles cometidas por la policía y el aparato represivo establecido paralelamente por las fuerzas armadas. (Assis de Almeida, 2006, p. 390 - la traducción es nuestra)

El hecho es que la dictadura militar fue un fenómeno complejo que muestra el poder de las fuerzas armadas en la historia brasileña. A partir de 1950 la orientación autoritaria de estas fuerzas se consolidó, desarrollándose el concepto de "seguridad nacional" como una doctrina para orientar la política de Brasil. Frente al crecimiento de las posturas de oposición se conformó otro concepto, el de "enemigo interno", no sólo para referirse a la oposición guerrillera $0 \mathrm{a}$ grupos subversivos, sino para etiquetar a cualquier expresión política que se oponía a ese modelo de modernización conservador y capitalista que ponía en peligro la estabilidad del Estado y la integridad de quienes lo encarnaban. Con base en esta idea se fraguó el golpe militar de 1964, cuando se consideró que el gobierno de João Goulart estaba bajo la influencia de fuerzas radicales o de izquierda. La complejidad del periodo de la dictadura militar ameritaría un trabajo sobre la manera en que se expresaron diferentes formas de resistencia: desde aquellas que tienen que ver con la lucha armada, la movilización y organización ciudadana, hasta las expresiones generadas desde la academia o el papel de manifestaciones artísticas (como el teatro) que en algunas regiones de Brasil hicieron críticas a la dictadura militar (Priore, 2010; Behring y Boschetti, 2008).

En ese contexto, en los últimos años de la dictadura militar, José de Picchia, periodista del periódico Folha de S.Paulo, se afilió a finales de la década de los años setenta al Partido do Movimento Democrático Brasileiro (PMDB), el cual se consolidó como el principal partido opositor de la dictadura militar en Brasil. El periodista originario de Piracicaba escribió un manifiesto que iniciaba con la siguiente expresión: "Piracicaba antes de haber sido ciudad, ya era río. Y fue ese río, por muchas décadas, el alma de la ciudad" (Picchia, 1982, p. 39). Este periodista describe que antes de la década de 1980 toda el agua del río Piracicaba se podía beber; sin embargo, en 1977 durante 
la nueva administración municipal la situación ya era caótica:

[...] de los grifos de la casa fluía un líquido amarillento y fétido, nada semejante al agua cristalina que se daba a los ciudadanos antes del estallido del "progreso" de las tres últimas décadas. Recuperar el Piracicaba a corto plazo era una tarea imposible, una vez que a lo largo de su cauce intermunicipal centenas de industrias - plantas de alcohol y azúcar, metalúrgicas y tejidos - lanzan enormes cantidades de desechos. La solución, por lo tanto, era construir una nueva captación de agua en una fuente más limpia. (Picchia, 1982, p. 39 - la traducción es nuestra)

Estos fueron los antecedentes de aquello que en la ciudad de Piracicaba llamaron "La lucha por el agua", considerada como "una batalla" en la que se trataron de crear, por un lado, condiciones materiales y técnicas con el fin de implementar una nueva estación captadora de agua potable; y por el otro, movilizar políticamente a la población para expresar descontento por la contaminación del río y exigir soluciones técnicas y ambientales que tuvieran repercusiones en la calidad de vida de los ciudadanos. Así, el movimiento que denunciaba la contaminación del río Piracicaba y exigía acciones para iniciar su saneamiento movilizó a todas las fuerzas sociales de la ciudad, incluso, a los grupos más conservadores.

Entre 1978 y 1979 el movimiento logró cobertura en diferentes medios de comunicación: diarios regionales (televisión y radio) del estado de São Paulo. De acuerdo con los testimonios de quienes participaron en aquel tiempo, en el movimiento se realizaron varios actos simbólicos, como aquel en el que se inauguró en la margen del río una plaza, llamada "La Plaza de la Protesta Ecológica", donde se colocó una bandera negra que para 1982, de acuerdo con el testimonio de Picchia, todavía estaba ondeando y expresaba una señal de luto por la muerte del río que durante muchas décadas además de dar nombre a la ciudad fue el soporte productivo y de abastecimiento de agua potable. Como señala Picchia (1982, p. 41):

El movimiento, además de ganar simpatía de la opinión pública sobre la necesidad de una nueva captación, fue un factor de concientización popular pues sirvió para mostrar que, en un río como el Piracicaba, que atraviesa por más de 40 ciudades, no se puede acabar con la contaminación a nivel municipal. Esta es una tarea a ser emprendida por el gobierno del estado. (La traducción es nuestra)

Algunas de las grandes enseñanzas del movimiento fueron considerar que el problema de la degradación del río afecta a muchos municipios, que las soluciones deben de plantearse con base en la integración de varios actores sociales y que es estrecha la relación entre política y gestión de recursos naturales, como se puede apreciar en la decisión que tomó el gobierno del estado de São Paulo para satisfacer la demanda de agua potable de la capital del estado por el crecimiento urbano de su región metropolitana. Por ello, en el movimiento de Piracicaba la población tomó conciencia de que en la medida en que el gobierno goce de mayor legitimidad, habrá mejores posibilidades de diálogo, negociación e interés por los problemas medio ambientales que por mucho tiempo habían sido relegados. Mientas 
esto no suceda, los problemas ambientales, de contaminación y abasto de agua seguirán agudizándose (Hernández, 2015).

De acuerdo con Moore (1996), algunos actores sociales buscan sobreponerse a la autoridad moral del sufrimiento y la opresión, a través de la persuasión y la acción para buscar cambios en el orden social. En este proceso, prevalecen problemas y formas de injusticia social que afectan de forma colectiva. La creación de formas de organización es la expresión del descontento y es una manifestación del sentimiento de agravio moral. Para los ciudadanos de Piracicaba, ver las condiciones en la que se encontraba su río fue el principal motor que generó formas de acción social que agrupó a diversos actores sociales. Siguiendo los registros de Picchia se aprecia que:

[...] La gente se dio cuenta de que no podía confiar en los gobiernos ilegítimos, impuestos por un sistema neo-feudal, donde los gobernadores en primer lugar deben rendir homenaje al señor de Brasilia y la baronía de tecnoburocracia. Los piracicabanos sentían en el estómago, en el paladar, los efectos de las decisiones tomadas en los gabinetes de los palacios, sin consulta popular. Con la creación, de parte de Sabesp (la empresa de saneamiento básico del estado de São Paulo), del sistema Cantareira para abastecer de agua a la región de la Grande São Paulo, el lecho del río estuvo más densamente contaminado, cuando enormes cantidades de sus aguas fueron desviadas para que, después de ser tratadas, sirvieran a los paulistanos. La situación se agravó tanto que los piracicabanos no bebían más agua; "tomaban caldo de mierda", decía de manera irónica el conductor profesional,
José Leite, del barrio de Nueva América; "era común que salieran lombrices en los grifos de las casas", continuaba diciendo. (Del Picchia, 1982, p. 40 - la traducción es nuestra)

Si bien el movimiento que tuvo sus orígenes desde finales de la década de los años setenta e inicios de los ochenta, fue entre 1985 y 1988 que éste lideró el mayor movimiento social en defensa del río y que tuvo una notable influencia en la creación de nuevos modelos de gestión de agua potable y saneamiento. En ese marco, fue fundamental el papel de actores sociales con formación técnica y académica para fortalecer los argumentos sobre los que sustentó el movimiento y proponer alternativas de solución. La Asociación de Ingenieros y Arquitectos de Piracicaba ${ }^{1}$ fue el principal actor social que estuvo al frente del movimiento. Esta asociación estaba conformada en su mayor parte por ingenieros civiles, ingenieros agrónomos y arquitectos, es decir, ciudadanos cuyas profesiones tenían estrecha mucha relación con los aspectos urbanísticos. Así, la División del Medio Ambiente de la Asociación organizó reuniones, seminarios locales y la elaboración de diagnósticos en los cuales se exponían los niveles de degradación del río Piracicaba, todo ello con el fin de encontrar alternativas para su saneamiento. Las convocatorias tuvieron impacto en la sociedad, y al paso de algunos meses ya se habían sumado los esfuerzos de otras asociaciones, organizaciones de la sociedad civil como el Consejo Coordinador de Entidades Civiles de Piracicaba, integrando así a importantes líderes locales, organizaciones civiles, empresarios y autoridades locales (Monticeli, 1993, p. 38). 
El movimiento fue llamado "Campaña año 2000 - Redención Ecológica de la Cuenca del Río Piracicaba". De esta manera, ya con una identidad consolidada, en la ciudad de Piracicaba y otros municipios vecinos se llevaron cabo reuniones, manifestaciones públicas, foros y seminarios en donde se alertaba de la compleja situación de degradación por la que estaba atravesando el río. La Asociación de Ingenieros y Arquitectos de Piracicaba se dio a la tarea de sumar los esfuerzos de sus miembros para elaborar documentos que le dieran sustento político y técnico a sus movilizaciones. El más importante fue la "Carta de Reivindicaciones al gobierno de Orestes Quércia", conformada por 32 diferentes reivindicaciones hacia los poderes públicos del ámbito estatal. Se trata de una dura crítica hacia las acciones realizadas por las distintas secretarías de estado, especialmente las que tienen que ver con la administración de servicios de agua potable, saneamiento $y$, en general, la gestión de recursos hídricos. En el documento se critica a la Compañía de Tecnología y Saneamiento Ambiental (Cetesb), instancia ligada a la Secretaría del Medio Ambiente del gobierno de estado de São Paulo y creada el 28 de julio de 1968 a través del decreto No. 50.079 para otorgar permisos a empresas que realizaban diferentes actividades productivas, además de monitorear y vigilar todo de tipo de actividades que implicaran la contaminación de afluentes.

En 1985, los ingenieros Nelson Rodrigues y José Elidney Pinto, dos de los principales líderes del movimiento, exigieron que toda la cuenca del Río Piracicaba fuera indemnizada por los daños que le había causado el Sistema Cantareira, el principal responsable de las cada vez más frecuentes sequías en el interior del estado (Comunicación personal con José Carlos Perdigão, Asociación Jaguatibaia, Sousas, Campinas, diciembre de 2014). Esta demanda formó parte de la reivindicación número 28 y hoy en día forma parte de la legislación estatal de gestión del agua. Las reivindicaciones 29 y 30 exigen que los recursos recabados de la indemnización sean obligatoriamente aplicados a inversiones que tengan que ver con la construcción de obras y servicios para la regeneración del entorno ambiental; es decir, que sean recursos destinados a la mitigación de daños al medio ambiente. Dentro de las prioridades, se exige mayor atención al problema del alcantarillado y tratamiento de aguas residuales así como a la reforestación en las márgenes del río. Por otro lado, la reivindicación 31 plantea "que estos recursos sean recolectados para el Organismo Intermunicipal de la Cuenca del Piracicaba".

En ese sentido, la formación de figuras intermunicipales también fueron demandas del movimiento, ya que se tuvo la visión de que los problemas de contaminación del río no se podían atender de manera aislada. La degradación del río afectaba a otros municipios porque en términos hídricos están interconectados. Por otro lado, la conformación de estas figuras intermunicipales colegiadas promoverían una gestión de recursos descentralizada, con la participación directa de ciudadanos, municipios y particulares que están directamente vinculados con el río Piracicaba. Una parte significativa de las demandas del movimiento estuvieron orientadas a esos objetivos, como lo destaca Monticeli (1993, p. 40): 
Interpretando las reivindicaciones de la "Campaña Año 2000", a la luz de los modelos de gestión, de experiencias internacional y de propuestas nacional de legislación en recursos hídricos vemos que el movimiento de Piracicaba fue pionero. Estaba y está en pauta, la lucha por la descentralización para que los recursos planeados sean gestionados por las autoridades municipales y para que tengan un destino claro: tratamiento de aguas residuales y reforestación. No es de extrañar que la organización en 1989 del Consorcio Intermunicipal de las Cuencas de los ríos Piracicaba Capivari y sus programas y banderas de lucha hayan recaído principalmente sobre esos puntos y reivindicaciones anteriormente citados. (La traducción es nuestra)

La presión política del movimiento obligó al gobernador a promulgar el Decreto 28.489, el 9 de junio de 1988, en el que se declaró a la cuenca del Río Piracicaba como modelo de gestión. A partir de esta iniciativa se destinaron recursos monetarios y se elaboraron programas de las secretarias para ser implementados en la cuenca del Piracicaba. Así, ésta se convirtió en la prioridad del gobierno estatal, por lo menos en teoría, porque en la práctica la situación era mucho más compleja. Al respecto, Monticeli (1993, p. 39) explica:

[...] en el círculo técnico, en los discursos, informes - en el papel como dicen - la cuenca del Piracicaba aparece tan crítica como la fuente principal que se debe proteger. En el presupuesto, la liberación de recursos que realmente contienen otras empresas, entre ellas algunas notoria falta de unanimidad, por no hablar de otras cosas, como el caso de la excavación para el río Tietê del descenso en la Región Metropolitana de São Paulo, que debería consumir cientos de millones de dólares. (La traducción es nuestra)

El movimiento por el saneamiento del río Piracicaba se caracterizó, entre otros aspectos, por la generación de una conciencia ecológica en los ciudadanos; no sólo en el municipio del mismo nombre, sino en municipios vecinos que también dependen del río para sus actividades productivas o para el abastecimiento de agua potable. Así, la definición de nuevos principios en la gestión de agua y la creación de espacios de discusión y deliberativos son los resultados más significativos de esa movilización. Como se puede apreciar, existieron condiciones histórico-sociales propias del contexto brasileño de permitieron estos procesos de acción colectiva y dieron origen a formas de participación social que años después, con la promulgación del la constitución de 1988, se fortalecerían. Esto no significa que todo ello se haya traducido en un éxito rotundo, pero marcó la pauta para la inclusión de la sociedad civil por lo menos durante algún tiempo en espacios de decisión.

\section{Un nuevo modelo de gestión: el Consorcio Intermunicipal}

La creación del Consorcio Intermunicial de los ríos Piracicaba, Capivari y Jundiaí (Consorcio PCJ) en 1989 es una de las expresiones organizativas con un significativo impacto regional. Se trata de una asociación de municipios que a partir de la integración de prefeitos (ediles), vereadores (concejales) y organizaciones civiles lucharon por el saneamiento del río Piracicaba (Liana, 2010; 


\section{Cuadro 2 - Escenario político y ambiental en Piracicaba}

\begin{tabular}{|c|c|c|}
\hline & Décadas 1960-1970 & Décadas 1980-1990 \\
\hline $\begin{array}{l}\text { Escenario político } \\
\text { en Brasil y en Piracicaba }\end{array}$ & $\begin{array}{l}\text { - } 1964 \text { - Golpe militar en Brasil. } \\
\text { - } 1964 \text { - "Marcha por la Familia con Dios por la } \\
\text { Libertad" en Piracicaba. } \\
\text { - } 1964 \text { - "Passeata de los estudantes" en } \\
\text { Piracicaba. }\end{array}$ & $\begin{array}{l}\text { - } 1985 \text { - Transición de la Dictadura hacia un } \\
\text { sistema democrático en Brasil. } \\
\text { - 1989-1992 - Presupuesto Popular. } \\
\text { (Antecedente importante del Presupuesto } \\
\text { Participativo en Brasil). }\end{array}$ \\
\hline $\begin{array}{l}\text { Escenario en la gestión } \\
\text { de recursos hídricos }\end{array}$ & $\begin{array}{l}\text { - 1960-1970 - Fortalecimiento de la industria y } \\
\text { agroindustria en Campinas. } \\
\text { - 1960-1975 - Incremento en la demanda de } \\
\text { agua potable para la Grande São Paulo. } \\
\text { - 1960-1976 - Construcción de las primeras } \\
\text { represas del Sistema Cantareira para garantizar } \\
\text { agua a São Paulo. } \\
\text { - 1978-1979 - Intensificación de los } \\
\text { problemas de falta de agua, como efecto de } \\
\text { la implementación del Sistema Cantareira y } \\
\text { la contaminación del río Piracicaba, producto } \\
\text { del auge de las actividades industriales en } \\
\text { Campinas. Inauguración de la "Plaza de la } \\
\text { Protesta Ecológica". }\end{array}$ & $\begin{array}{l}\text { - } 1982 \text { - Manifesto "La lucha por el agua". } \\
\text { - } 1985 \text { - Inicia movimiento de la Asociación de } \\
\text { Ingenieros y Arquitectos de Piracicaba; Consejo } \\
\text { Coordinador de Entidades Civiles de Piracicaba. } \\
\text { - } 1985 \text { - Creación del movimiento "Campaña } \\
\text { Año } 2000 \text { - Redención Ecológica de la Cuenca } \\
\text { del Río Piracicaba". } \\
\text { - } 1985 \text { - Elaboración de la "Carta de } \\
\text { Reivindicaciones al Gobierno Orestes Quércia", } \\
\text { con pliego de demandas. } \\
\text { - } 1985-1988 \text { - Consolidación del Movimiento } \\
\text { con la confluencia de varios actores sociales, } \\
\text { especialmente la La Asociación de Ingenieros y } \\
\text { Arquitectos de Piracicaba. } \\
\text { - } 1989 \text { - Formación del Consorcio } \\
\text { Intermunicipal de los Ríos Piracicaba, Capivari } \\
\text { y Jundiaí. }\end{array}$ \\
\hline
\end{tabular}

Fuente: Hernández (2015).

Monticelli, 1993, p. 98). Por otro lado, es una respuesta al fracaso de los tradicionales modelos en la ejecución de políticas públicas en abastecimiento de agua, saneamiento y medio ambiente en Brasil. Se trata de efecto de las campañas y luchas de entidades civiles de la región, especialmente de la "Campaña Año 2000 - Redención Ecológica de la cuenca del rio Piracicaba". Si bien en los municipios participantes había un interés común, el saneamiento del río Piracicaba, y la implementación de adecuados mecanismos de gestión de agua, el reto que implicó la formación del consorcio intermunicipal fue la construcción de acuerdos en una región compuesta por actores sociales heterogéneos, con diferentes agendas, proyectos y posturas políticas. Con todo ello, el 13 de octubre de 1989, con la participación de 12 alcaldes, de un total de 46, se conformó la primera dirección del Consorcio y los primeros municipios que lo integraron fueron Americana (PDT), ${ }^{2}$ Amparo (PDS), ${ }^{3}$ Bragança Paulita (PL), ${ }^{4}$ Campinas (PTPDT), ${ }^{5}$ Capivari (PMDB), ${ }^{6}$ Cosmopolis (PT), ${ }^{7}$ 
Jaguariúna (PMDB), Joanópolis (PMDB), Pedreira (PDC), ${ }^{8}$ Piracicaba (PT), Rio Claro (PL) y Sumaré (PTB). ${ }^{9}$ Como se puede apreciar, la participación de varios alcaldes implicó una significativa presencia de diversos partidos políticos por la adscripción que tenían estos actores sociales. De esta manera, el Consorcio más que ser un frente político supra-partidario reúne a municipios de especial importancia para la economía del país, los cuales hacia finales de la década de los años noventa eran los responsables del $10 \%$ del PIB a nivel nacional. Una de las prioridades de los consorciados, quizá la más significativa para en esa coyuntura, fue la conformación de un fondo regional para el financiamiento de programas de protección y saneamiento del río Piracicaba y otros afluentes con importancia a nivel regional o local (Hernández, 2015).

Llegar a acuerdos también fue un proceso complejo y en algunos momentos tenso porque quienes vivieron de cerca este proceso coinciden en que la integración de alcaldes, incluso del mismo partido, fue una tarea complicada, sobre todo si se considera que en la tradición política brasileña de ese periodo estaba caracterizada por la desconfianza y la existencia de intereses personales por encima del bien común; además, existía una sólida dependencia de los municipios de las decisiones del gobernador del estado, como lo indica Monticeli (1993, p. 60):

Las necesidades municipales serían resueltas por solicitud del diputado, amigo de quienes están al lado de los detentores del poder. El fracaso de las finanzas públicas muestra que la realidad es diferente, principalmente si se trata de la problemática ambiental relativa al agua y alcantarillado, que expone a las autoridades locales diariamente frente a las reivindicaciones de la población. (La traducción es nuestra)

Consolidar una expresión como el Consorcio implicó un complejo trabajo político expresado en un año de negociaciones. De un total de 29 municipios involucrados en un primer momento, sólo llegaron a acuerdos 12, que ya representaban al $60 \%$ de la población de toda la cuenca. El importante testimonio de Monticelli da cuenta de la complejidad en las negociaciones y cómo éstas se fueron llevando a cabo en diferentes espacios, algunos formales, otros informales; incluso, cómo situaciones tan imprevistas en determinado momento definieron el rumbo de las decisiones, como lo expresa en el siguiente testimonio:

Nicola Cortés, entonces alcalde de Bragança Paulista, tierra del famoso "Club de Futbol Bragantino", digo y agendó una reunión en Piracicaba con José Machado. La idea del señor Nicola, hombre de negocios en Bragança Paulista, era conversar sobre el río Piracicaba, sobre cómo tratar las aguas residuales, cómo sanear el río, reuniendo al principal municipio y otros de más abajo del río Piracicaba. Nicola cree, al igual que Machado, con quien nunca había hablado antes, en convocar una reunión de alcaldes. Machado convende a Nicola de que Campinas, por ser la ciudad con mayor importancia y la que más contamina, debería ser la primera en la reunión. Comienza ahí la promoción de Machado para que el alcalde de Campinas, Jacó Bittar, fuera el presidente del Consorcio. Se comienza también a crear legitimidad en la participación de Nicola en la futura dirección del Consorcio. En un almuerzo en Campinas 
entre Machado y Jacó se define el apoyo del primero al segundo un mes antes de la elección. El peso de PT era considerable porque tenía influencia en las ciudades de Campinas, Piracicaba y Cosmópolis, y estaba aliado al PDT en Americana. Por lo tanto, se contaba con cuatro votos. Pero no fue correctamente evaluado que la mayoría estaba compuesta por los votos de los demás municipios, quienes no estaban aún decididos para la elección del presidente.

Durante dos horas los alcaldes de las doce ciudades estuvieron reunidos para escoger la primera dirección del Consorcio. Los cuatro alcaldes citados defendían a Jacó y los demás a Machado. Cuando parecería que todo estaba decidido y Jacó sería escogido, el arquitecto Antonio Costa Santos, Toninho, sub alcalde de Campinas y representando al alcalde Jacó - se retiró de la reunión para recibir al gobernador Quércia en Campinas, dificultado de manera decisiva el apoyo a su nombre - se ausenta por algunos minutos de la sala de la reunión. Cuando regresa, Machado había aceptado ser el presidente, bajo amenaza enfática de Paulino Carrar y Carlos Píffer de retirarse del Consorcio que acababan de fundar. Tras todo, Campinas, la mayor ciudad de la región quedó casi un año sin participar en el Consorcio. Fueron necesarias varias reuniones de entidades civiles, ambientales y alcaldes para convencer a Jacó a participar en el Consorcio. Machado y Nicola fueron reelectos presidente y vicepresidente un año después, con el apoyo del propio Jacó. El Consejo Fiscal de aquella época, teniendo al frente como presidente al médico Odair Schafer, de Campinas, también fue reelecto. (La traducción es nuestra)
El prestigio que ha alcanzado el Consorcio en la región tiene mucho que ver con su independencia política con el estado y la federación. De acuerdo con el testimonio de José Carlos Perdigão, las condiciones políticas de ese momento permitieron el inicio de un proceso democrático en Brasil, complejo, pero que tenía una clara orientación hacia "un tipo de independencia y cultura propia, organizada de abajo para arriba; y solamente los líderes políticos capaces de entender los nuevos tiempos, las nuevas formas de hacer política, son capaces de sacar adelante tal desafío".

Con base en lo que se ha descrito, los problemas y conflictos generados a partir de la relación entre sociedad y recursos hídricos motivaron la acción de ciudadanos y dieron origen a nuevos mecanismos de organización intermunicipal para hacer frente a la degradación de los principales afluentes de la región. Además, en ese territorio existieron condiciones políticas en diferentes ámbitos para que se generara un movimiento de amplias dimensiones y con capacidad de incidencia en las políticas públicas de gestión hídrica en Brasil. El movimiento de ciudadanos es un hecho recurrente por los innumerables proyectos de desarrollo que estuvieron y que todavía están en puerta. En el contexto de la implementación de proyectos de desarrollo, como fue el Sistema Cantareira o la construcción de algunas termoeléctricas, los ciudadanos han contado con una significativa capacidad de respuesta. Uno de los ejemplos en esa etapa fue el proyecto de la construcción de una termoeléctrica en el municipio de Paulinia. La industria desarrollada en los 
municipios de Campinas y Paulínia por muchas décadas generó el ecosistema del municipio, especialmente en sus recursos hídricos. En 1988 se hizo público un proyecto de la Compañía Energética de São Paulo (Cesp) ${ }^{10}$ que consistía en la construcción de una termoeléctrica en el municipio de Paulínia. Este municipio, además, cuenta con una de las refinerías más grandes de todo Brasil (Petrobrás) y desde inicios de la década de los años setenta incursionó en el desarrollo de la industria petroquímica. Otro ejemplo del desarrollo de la industria es el caso del Centro Industrial Shell, también ubicado en Paulinia y que ha generado altos niveles de contaminación en los pozos de agua utilizada por los habitantes de la ciudad para uso doméstico.

En ese contexto, las organizaciones ambientalistas cuestionaron los efectos que podría generar la construcción de la termoeléctrica y se inició un movimiento que agrupó a alcaldes, ediles y al Consorcio Intermunicipal de las Cuencas de los ríos Piracicaba y Capivari. Éste último promovió la realización de diversos foros para discutir el problema. Además, centros de investigación como el Núcleo de Estudos e Pesquisas Ambientais (Nepam) de la Unicamp y otros grupos de la universidad elaboraron documentos de divulgación con los resultados de sus investigaciones, cuestionando la viabilidad de dicho proyecto. Entre los años 1988 y 1992 se dieron acaloradas discusiones donde, incluso, dentro de la misma universidad había posturas encontradas; es decir, algunos investigadores veían la viabilidad técnica y financiera del proyecto, mientras que otros que ponían énfasis en los efectos sociales y ambientales de toda la región. Finalmente, en medio de mucha presión, el gobernador del estado de São Paulo Luis Antonio Fleury anunció el 4 de junio de 1992, dentro del Foro Global celebrado en Río de Janeiro, la cancelación del proyecto en Paulínia (Correio Popular, 5 de junio de 1992). Tras su declaración, la movilización paulatinamente perdió fuerza. Sin embargo, meses después las declaraciones sobre la posibilidad de reactivar el proyecto comenzaron a ser más frecuentes. Los promotores del proyecto esperaban que los tiempos políticos les fueran más favorables, aprovechando el próximo proceso electoral. Así, con el reacomodo de fuerzas políticas el proyecto se siguió impulsando pero dentro de las márgenes del río Mogi Guaçu, fuera del área del río Piracicaba. Este tipo de experiencia pone en relieve la estrecha relación entre política, desarrollo y medio ambiente, por un lado, y por otro, una significativa capacidad de respuesta de varios sectores de la población, principalmente aquellos vinculados a trabajo ambiental e intelectuales, personas con conocimiento técnicos de las implicaciones ambientales de la implementación de proyectos de desarrollo.

Después de este dinámico proceso de movilización social, se dio inicio a un complejo proceso de institucionalización de las demandas de la sociedad organizada no sólo en la ciudad de Piracicaba, sino en todos los municipios que también forman parte de la cuenca. Los impactos se hicieron evidentes en su legislación, dando un espacio central para la participación de la sociedad civil, a pesar de las distintas limitaciones que existen en ese ámbito, puesto que, como lo plantea Abers (2009), estos espacios han sido institucionalizados, burocratizados y en algunos 
casos, las discusiones que se presentan siguen siendo técnicas. Esta fuerte institucionalización tiene sus orígenes en el modelo de gestión de agua francés, el cual le da importancia central a la participación de la sociedad civil en la gestión de agua. Líderes y miembros del Consorcio fueron a Francia y estudiaron ese modelo para elaborar uno alterno acorde a las necesidades de Brasil. Así, en 1990 el Consorcio inicia una discusión para crear un nuevo modelo de gestión de agua, basado en tres principios básicos: una gestión descentralizada, dotando a las instancias locales de poder de decisión sobre sus recursos hídricos; una gestión incluyente, en la cual actores sociales (usuarios, empresas, gobierno) estén incluidos en los procesos de administración de recursos hídricos, especialmente en el marco de problemas de escasez y contaminación de ríos; y finalmente una gestión sustentable que tome las providencias necesarias (técnicas y sociales) para mitigar los efectos de las diversas actividades productivas o usos urbanos del agua.

Con base en esa experiencia, en 1991 se promulgó la Ley Estatal 7.663 que retoma dichos principios de gestión descentralizada en São Paulo. Seis años más tarde, se aprobó la Ley de Recursos Hídricos n. 9.433, que sienta las bases para la creación de mecanismos de cobro y la formación de Organismo de Cuenca Hidrográfica. En 1998 se hace público el Decreto Federal 2.612 en el que se consolida la política nacional de recursos hídricos a través de la instalación del Consejo Nacional de Recursos Hídricos. En el año 2000 se aprobó la Ley 9.984/2000 a través de la cual se crea la Agencia Nacional de Aguas en Brasil (ver Cuadro 3).
El Consorcio Intermunicipal PCJ hoy en día sigue siendo un referente en las discusiones en torno a la gestión de recursos hídricos. Participa de manera activa en discusiones en espacios académicos y aquellos organizados por instancias gubernamentales en el estado de São Paulo. Uno de sus fundadores, Francisco Lahoz, se ha convertido en actor central en la difusión de la problemática en torno a la gestión de recursos hídricos y, especialmente, ha enfocado el trabajo del Consorcio a la realización de planes educativos para hacer conciencia de la importancia de una gestión integral, justa e inclusiva en todos los sectores de la sociedad. La concientización es una de sus tareas fundamentales, así como la búsqueda de alternativas en los actuales contextos donde no sólo los frutos del movimiento de Piracicaba se han institucionalizado, sino ante los desafíos como los que se manifiestan en las recurrentes crisis hídricas que desde 2013 han afectado severamente al estado de São Paulo. El papel del Consorcio ha sido central, sin embargo, en la actualidad vale la pena cuestionar si han sido suficientes los principios que defendió en un primer momento; por otro lado, es importante pensar en los retos de la sociedad y el gobierno brasileño ante las recurrentes crisis hídricas, así como la búsqueda soluciones integrales que no enfaticen sólo salidas técnicas en los procesos de gestión de agua.

\section{Conclusiones}

El caso aquí analizado pone en relieve procesos participativos en torno a la gestión de agua potable, saneamiento y recursos naturales; es decir, la manera en que actores sociales 


\section{Cuadro 3 - Trayectoria de la lesgilación de aguas en Brasil}

\begin{tabular}{|c|l|l|}
\hline Año & \multicolumn{1}{|c|}{ Acción } & \\
\hline 1934 & Código de aguas & $\begin{array}{l}\text { Primeros momentos para regular gestión de recursos hídricos } \\
\text { orientada a la generación de energía eléctrica y fortalecimento de } \\
\text { actividades agrícolas }\end{array}$ \\
\hline 1989 & Creación del Consorcio PCJ & $\begin{array}{l}\text { Conformación como fuerza política para incidir en el gobierno } \\
\text { estatal y federal en el saneamiento y preservación de ríos }\end{array}$ \\
\hline 1990 & $\begin{array}{l}\text { Articulación de los Consorcios para incidir en la Ley } \\
\text { Estatal y Federal de Recursos hídricos }\end{array}$ & $\begin{array}{l}\text { Los Consorcios empujan hacia la creación de un nuevo modelo de } \\
\text { gestión de agua }\end{array}$ \\
\hline 1991 & Promulgación de la Ley Estatal 7.663/1991 & $\begin{array}{l}\text { En el artículo 28 se promueve la creación de Agencias de Cuencas } \\
\text { como un mecanismo de descentralización }\end{array}$ \\
\hline 1992 & $\begin{array}{l}\text { Investigación y estudios sobre esquemas de gestión } \\
\text { en otros países, especialmente Francia y Alemania }\end{array}$ & $\begin{array}{l}\text { Consolidación de la idea de sistemas descentralizados e } \\
\text { incluyentes a los actores sociales }\end{array}$ \\
\hline 1993 & Creación del Comité de Cuencas & Se dan las bases para la creación de una Agencia Nacional \\
\hline 1998 & Aprobación de la Ley de Recursos Hídricos n. 9.433 & $\begin{array}{l}\text { Bases para la creación de mecanismos de racionalización, cobro y } \\
\text { formación de Organismos de Cuenca Hidrográfica }\end{array}$ \\
\hline 2000 & Aprobación de la ley 9.984/2000 & $\begin{array}{l}\text { Consolidación de Política Nacional de Recursos Hídricos a través } \\
\text { de la instalación del Consejo Nacional de Recursos Hídricos }\end{array}$ \\
\hline Aprobación del decreto 50.667 & Creación de la Agencia Nacional de Aguas \\
\hline
\end{tabular}

Fuente: Hernández (2015).

heterogéneos se interrelacionan en espacios públicos y arenas sociales caracterizadas por situaciones de tensión, conflicto y disputa. Como señala Isunza (2006a, p. 266), la participación ciudadana:

[...] es la relación entre ciudadanos y Estado en diferentes formas y con diversas intensidades e intencionalidades [...] organizados para exigir cuentas a los funcionarios públicos o demandar un servicio, o con la finalidad de elegir a los representantes o quejarse por un bien mal distribuido, en cualquier caso los ciudadanos movilizan energías y recursos en un flujo continuo de intercambio con las instituciones del Estado.
Así, los actores sociales a los que se ha hecho referencia en este análisis son parte de aquello que conceptualmente se denomina sociedad civil, encarnada en colectivos, asociaciones y organizaciones no gubernamentales con trayectorias, agendas y proyectos políticos que determinan las diversas formas asociativas que los actores sociales consideren más funcionales. La noción de proyecto político en términos analíticos es una contribución que permite identificar contenidos y formas en contextos de confrontación de proyectos ya sean alternativos o liberales frente a visiones conservadoras o autoritarias. Dagnino (2006, p. 44) define la categoría 
de proyecto político como el conjunto de creencias, intereses, concepciones del mundo y representaciones de lo que debe ser la vida en sociedad y que "orientan la acción política de los diferentes sujetos".

El caso de la ciudad de Piracicaba y toda su región se constituye como un ejemplo sobre la manera en que se expresan los proyectos políticos de los actores sociales. En Brasil la transición de la dictadura militar hacia la Asamblea Constituyente significó históricamente una "ruptura de equilibrios previos y la irrupción de nuevos actores en el escenario", abriendo oportunidades "para consagrar la participación como un principio del Estado" (Isunza, 2014, p. 39). Los movimientos de ciudadanos organizados en diferentes momentos de la historia de Brasil, sin duda, han empujado hacia la consolidación de procesos democráticos que aún y con las limitaciones que pudieran existir ofrecen a los ciudadanos garantías para poder exigir a las autoridades $y$, en algún momento, poder incidir en la formulación de políticas públicas, tal como ocurrió a partir del movimiento en Piracicaba. En ese sentido, sería importante hacer una reflexión sobre el momento que se está viviendo en Brasil, donde los espacios de participación han quedado burocratizados y donde el proyecto político que prevalece es el un neoliberalismo no tiene interés alguno en el desarrollo de principios sustentables, mucho menos de participación colectiva.

Los movimientos sociales transformaron a Brasil en el modo de hacer política, novedad que según Feltran (2006, p. 430) consistió en la renovación de espacios y sujetos sociales; es decir, el resurgimiento de la sociedad civil brasileña. El nuevo contexto político hizo posible una participación más abierta de las fuerzas vinculadas a la izquierda en espacios que décadas atrás simplemente no hubieran podido ocupar; de esta forma inició una paulatina ocupación de espacios dentro de la nueva institucionalidad política. Después de algunos años aquellos que empujaron hacia la reconfiguración de un nuevo Estado formaron parte de él.

Los elementos expuestos en esta aportación ayudan a entender la manera en que en el ámbito local y regional se han consolidado los espacios de concertación integrados por diferentes municipios para buscar soluciones a los problemas de degradación de ríos, gestión de agua potables o preservación del entorno ambiental. Para Dagnino (2006) el fenómeno asociativo como se encarna en el Consorcio $P C J$ es multidimensional, porque se reproduce en diferentes ámbitos de la vida social y son las propias asociaciones, heterogéneas en sí mismas, quienes tienen distintas capacidades de intervención en la vida pública. Las capacidades de las asociaciones no se determinan por su forma de organización, sino por sus circunstancias históricas.

El asociativismo intermunicipal tiene algunas características (Hernández, 2015): 1) en esencia tiene un carácter voluntario; 2) se respeta la autonomía municipal, manteniendo la naturaleza jurídica e institucional de cada municipio; 3) se acuerdan los medios, el tipo de organización y los esfuerzos para la acción común; y 4) las figuras asociativas por su naturaleza institucional son complejas y sus límites o alcances tienen que ver con la permanencia de identidades municipales y la necesidad de una administración horizontal. No crea una 
estructura política opuesta a la municipal y busca el fortalecimiento del municipio sin afectar otras entidades. Finalmente se considera que la intermunicipalidad crea una figura local que se caracteriza por ser un especio de colaboración, coordinación y capacidad de decisión.

Ese asociativismo intermunicipal no podría haberse dado sin el movimiento social en Piracicaba. Los desafíos y retos en el actual contexto son complejos, puesto que la ciudad continua siendo el escenario en el que se reproducen situaciones desigualdad en el acceso al agua, en cantidad y calidad suficiente para garantizar el bienestar de los ciudadanos. La crisis hídrica de São Paulo es sólo una muestra del cambio de escala y la nueva dimensión en la que están manifestando los problemas de escasez, deficiencia en la gestión y contaminación de recursos hídricos. Las aportaciones del movimiento socioambiental en la ciudad de Piracicaba en la conformación de un modelo de gestión de agua en Brasil fueron fundamentales, sin embargo, ante los nuevos escenarios la sociedad brasileña tiene un enorme desafío para hacer frente a estos problemas y tal vez iniciar una nueva lucha por el agua.

\section{[I] https://orcid.org/0000-0001-9194-6368}

Universidade Estadual de Campinas, Instituto de Filosofia e Ciências Humanas, Departamento de Demografía, Programa de Pós-Graduação em Demografia. Campinas, SP/Brasil.

miguel.hdez.hdez@gmail.com

\section{Notas}

(*) Las facilidades para la realización de este artículo han sido otorgadas por la Secretaría de Ciencia Tecnología e Innovación de la Ciudad de México, en el marco del Programa de Estancias Posdoctorales en Instituciones Académicas con Sede en Europa y América 2017. Por su parte, también recibí el apoyo del Núcleo de Estudos de População y el Instituto de Filosofia e Ciências Humanas de la Universidade Estadual de Campinas a través de mi estancia posdoctoral."

(1) La Asociación se fundó el primero de diciembre de 1964, algunos meses después del golpe militar de ese mismo año. Ha enfocado sus trabajos en la prestación de servicios urbanos a la ciudad de Piracicaba con base en el trabajo colaborativo de profesionales y autoridades municipales. Antes de consolidarse como una asociación, sus primeros miembros participaron en la revisión del Código de Obras del Municipio de Piracicaba, posteriormente aprobado por la Cámara de Concejales. Integró a profesionistas de las áreas técnicas y tecnológicas: ingenieros civiles, técnicos en edificaciones, ingenieros agrónomos, ingenieros forestales, electro-técnicos, ingenieros en telecomunicaciones, ingenieros mecánicos, ingenieros industriales, ingenieros químicos, aeronáuticos y metalúrgicos.

(2) Partido Democrático Trabalhista.

(3) Partido Democrático Social. 
(4) Partido Liberal.

(5) Partido do Trabalho y Partido Democrático Trabalhista.

(6) Partido do Movimento Democrático Brasileiro.

(7) Partido do Trabalho.

(8) Partido do Movimento Democrático Brasileiro.

(9) Partido Trabalhista Brasileiro.

(10) El proyecto de la Cesp contempló la construcción de dos unidades con 350 MW de potencia para cada uno y sería financiado por Eximbank, organismo del gobierno japonés.

\section{Referencias}

ABERS. R. N.; FORMIGA. J. R. M.; BEATE, F.; KECK. M. E. y LEMOS. M. C. (2009). Inclusão, deliberação e controle: três dimensões de democracia nos comitês e consórcios de bacias hidrográficas no Brasil. Ambiente e sociedade. Campinas, v. XII, n. 1, pp. 115-132. Associação Nacional de PósGraduação e Pesquisa em Ambiente e Sociedade Campinas, Brasil.

AGUAS DO MIRANTE (2014). Programa Piracicaba Rede 100\%. Fatos e retratos da universalização do saneamento em Piracicaba. Piracicaba, Equipav, AEGEA, Águas do Mirante, Prefeitura de Piracicaba, Samae.

ASSIS DE ALMEIDA, G. y PINHEIRO, P. S. (2006). "Derechos humanos, violencia urbana”. In: ISUNZA, V. E. e OLVERA. J. A. (eds.). Democratización, rendición de cuentas y sociedad civil: participación ciudadana y control social. México, Cámara de Diputados LIX Legislatura, Centro de Investigaciones y Estudios Superiores en Antropología Social, Universidad Veracruzana, Porrúa Editores, pp. 389410.

BEHRING, E. R. y BOSCHETTI, I. (2008). Política social. Fundamentos e história. São Paulo, Cortez. (Biblioteca Básica de Serviço Social, 2).

CARMO, R. L. (2001a). ¿A água é o limite? Redistribuição espacial de la população recursos hídricos no Estado de São Paulo. Tese de Doutorado. Campinas, Universidade Estatal de Campinas.

CARMO, R. L. y TAGNIN, R. (2001b). “Uso múltiplo da água e múltiplos conflitos em contextos urbanos: o caso do Reservatório Billings". In: HOGAN. D. J.; BAERNINGER. R. y PINTO DA CUNHA. J. M. e CARMO. R. L. (coords.). Migração e ambiente nas aglomerações urbanas. Campinas, Universidade Estadual de Campinas, Núcleo de Estudos de População/CNPq.

CONSÓRCIO INTERMUNICIPAL PCJ. Disponile en: https://agua.org.br/nossa-area-de-atuacao/. Acceso en: 1 jun 2019.

CORREIO POPULAR, 5 de junio de 1992.

COSTA, R. O. (2004). As águas do Piracicaba. Século XIX. São Paulo, Edição Instituto Histórico e Geográfico de Piracicaba - Serviço Municipal de Água e Esgoto. 
DAGNINO, E.; OLVERA, J. A. y PANFICHI, A. (2006). "Introducción. Para otra lectura de la disputa por la construcción democrática en América Latina". In: DAGNINO, E.; OLVERA, A. e PANFICHI, A. (coords.). La disputa por la construcción democrática en América Latina. México, Fondo de Cultura Económica, Centro de Investigaciones y Estudios Superiores en Antropología Social, Universidad Veracruzana.

FELTRAN, G. S. (2006). “Dislocaciones. Trayectorias individuales, relaciones entre sociedad civil y Estado en Brasil". In: DAGNINO, E. e OLVERA, A. (coords.). La disputa por la construcción democrática en América Latina. México, Fondo de Cultura Económica, Centro de Investigaciones y Estudios Superiores en Antropología Social, Universidad Veracruzana, pp. 399-449.

GALLO, Z. (2000). A defesa da qualidade das águas da bacía do Rio Piracicaba: o papel da Cetesb de todos nós. Dissertação de Mestrado. Campinas, Universidade Estadual de Campinas.

HERNÁNDEZ, H. M. (2015). Prácticas ciudadanas e institucionales en la gestión de agua potable y saneamiento en dos regiones hidropolitanas de México y Brasil. Tese de Doutorado. México. Centro de Investigaciones y Estudios Superiores en Antropología Social.

IBGE (2016). Cidades: Piracicaba - Caracterização Geral. IBGE.

INSTITUTO DE INVESTIGACIÓN Y PLANEACIÓN DE PIRACICABA (2010). Disponível em: http://ipplap. com.br/site/piracicaba-em-dados. Acceso en: 20 out 2015.

IPEF - Instituto de Pesquisas e Estudos Florestais (2006). Atlas rural de Piracicaba. Piracicaba, Ipef.

ISUNZA, V. E. (2001). Las tramas del alba: una visión de las luchas por el reconocimiento en el México Contemporáneo (1968-1993). México, Centro de Investigaciones y Estudios Superiores en Antropología Social, Miguel Ángel Porrúa.

(2006a). "Para analizar los procesos de democratización: interfaces socioestatales, proyectos políticos y rendición de cuentas". In: ISUNZA, V. E. e OLVERA, J. A. Democratización, rendición de cuentas y sociedad civil: participación ciudadana y control social. México, Centro de Investigaciones y Estudios Superiores en Antropología Social, LIX Legislatura de la Cámara de Diputados, Universidad Veracruzana, Miguel Ángel Porrúa Editores, pp. 265-291.

(2006b). "El reto de la confluencia. Las interfaces socioestatales en el contexto de la transición política mexicana”. In: DAGNINO. E. e OLVERA. J. A. (coords.). La disputa por la construcción democrática en América Latina. México, Fondo de Cultura Económica, Centro de Investigaciones y Estudios Superiores en Antropología Social, Universidad Veracruzana, pp. 275-329.

ISUNZA, V. E. y GURZA. L. A. (2014). “Develando causes recurrentes. Los controles democráticos no electorales como prácticas de resignificación en la constitución democrática". In: ISUNZA, V. E. (coord.). Controles democráticos no electorales y régimen de rendición de cuentas. En búsqueda de respuestas comparativas: México, Colombia, Brasil, China y Sudáfrica. México, Centro de Investigaciones y Estudios Superiores en Antropología Social, Centro de Contraloría Social y Estudios de la Construcción Democrática, pp. 9-62.

PERDIGÃO, J. C. (2014). Asociación Jaguatibaia, Sousas, Comunicación personal. Sousas, Campinas.

LIANA, J. y PYR, M. (2010). O valor da água. Primeiros resultados da cobrança nas Bacias PCJ. São Paulo, Camirim.

McADAM, D.; McCARTHY, J. D. y ZALD, M. N. (1999). “Oportunidades, estructuras de movilización y procesos enmarcadores: hacia una perspectiva sintética y comparada de los movimientos sociales". In: McADAM, D.; McCARTHY, J. D. y ZALD, M. N. (eds.). Movimientos sociales: perspectivas comparadas. Madrid, Ediciones Istmo (Serie Ciencia Política), pp. 21-47. 
MONTICELI, J. J. y SOARES, M. J. P. (1993). A luta pela água: nas bacias dos rios Piracicaba e Capivari. São Paulo, EME.

MOORE, B. (1996). La Injusticia: Bases Sociales de la Obediencia y la Rebelión. México, Universidad Nacional Autónoma de México.

PEÑA, F. (2013). "El misterio de la sed urbana: la ciudad como construcción hidráulica”. In: PEÑA, F. (coord.). La sed urbana: la ciudad como construcción hidráulica. San Luis Potosí, México, EI Colegio de San Luis, pp. 9-20.

PERLÓ, C. M. y ARSENIO, E. G. (2005). ¿Guerra por el agua en el Valle de México? Estudio sobre las relaciones hidráulicas entre el Distrito Federal y el Estado de México. México, Universidad Nacional Autónoma de México, Coordinación de Humanidades, Programa Universitario sobre Estudios de la Ciudad, Friedrich Ebert Stiftung.

PICCHIA, P. (1982). A batalha da colina (a democracia chega a Piracicaba). São Paulo, Coleção MPDG (Movimento de Profissionais por um Governo Democrático).

POLACOW, P. (2014). "Piracicaba sai às ruas: a Marcha pela Família com Deus e o protesto dos estudantes". In: VICENTINI, B. H. (org.). Piracicaba 1964. O golpe militar no interior. Piracicaba, Editora UNEP.

PRIORE, M. y VENÂNCIO, R. P. (2010). Uma breve história do Brasil. São Paulo, Planeta.

TARROW, S. (1999). “Estado y oportunidades: la estructuración política de los movimientos sociales”. In: McADAM, D.; McCARTHY, J. D. e ZALD, M. N. (eds.). Movimientos sociales: perspectivas comparadas. Madrid, Ediciones Istmo (Serie Ciencia Política), pp. 71-99.

TEIXEIRA, A. C. (2003). Identidades em construção: as organizações não-governamentais no processo brasileiro de democratização. São Paulo, Annablume/Fapesp/Instituto Polis.

TEIXEIRA, A. C. y CARMO, A. M. (2006). "Presupuestos participativos: proyectos políticos, cogestión del poder y alcance democrático”. In: DAGNINO, E.; OLVERA, A. e PANFICHI, A. (coords.). La disputa por la construcción democrática en América Latina. Fondo de Cultura Económica, Centro de Investigaciones y Estudios Superiores en Antropología Social, Universidad Veracruzana, pp. 192-242.

TEIXEIRA, M. T. M. C. (2009). Piracicaba no século XIX. Piracicaba, Instituto Histórico e Geográfico de Piracicaba, Equilibrio Editora/Prefeitura Municipal de Piracicaba/Secretaría de Ação Cultural.

TILLY, C. y WOOD, L. J. (2010). Los movimientos sociales, 1768-2008. Desde sus orígenes hasta Facebook. Barcelona, Editorial Crítica.

WHATELY, M. y CUNHA, P. (2007). Cantareira 2006. Um olhar sobre o maior manancial de água da Regiao Metropolitana de São Paulo. Resultados do Diagnóstico Socioambiental Participativo do Sistema Cantareira. São Paulo, Instituto Socioambiental.

Texto recebido em 15/mar/2019

Texto aprovado em 29/maio/2019 